\title{
The Ethical Turn: Communication as a Manifestation of the Ethical
}

\author{
Bilyana Martinovski \\ Department of Computer and Systems Sciences, Stockholm University, Stockholm, Sweden \\ Email: bilyana@dsv.su.se
}

Received 28 August 2013; revised 30 September 2013; accepted 9 October 2013

Copyright (c) 2014 Bilyana Martinovski. This is an open access article distributed under the Creative Commons Attribution License, which permits unrestricted use, distribution, and reproduction in any medium, provided the original work is properly cited. In accordance of the Creative Commons Attribution License all Copyrights (c) 2014 are reserved for SCIRP and the owner of the intellectual property Bilyana Martinovski. All Copyright (C) 2014 are guarded by law and by SCIRP as a guardian.

\section{Abstract}

This paper calls for an ethical turn in communication. It offers a re-evaluation of Weaver's metaphor on communication as exchanges of information and develops Buber's and Peters' ideas on communication as manifestation of the ethical, where the ethical is described as openness to otherness and communication is viewed as a tension between reproduction of Self and reconciliation with alterity. It argues that mutuality is not a necessary condition for the ethical because it involves intimacy that can only be discrete, and that end of theodicy is not the end of the ethical because the ethical is a space of profound intimacy, beyond preachment. Extreme cases of annihilation of otherness such as genocides in all their stages and variations, can't be described as rational in some cases than others and have deeper roots than modernity. The ethical turn within socio-political conflicts and genocidal process meets challenges such as the patriarchal order, implantations and involvement of the third, dehumanization, isolation for larger contexts, traumatic disorders, and states of denial. However, the potential of communication as reconciliation is enhanced by insights in intercultural communication, nurturing of hybrid cultures, and distance taking techniques such as time distance, attention/topic shift, emotions such as feelings of awe and art.

\section{Keywords}

Ethics; Communication Theory; Genocide; Theodic

\section{Introduction}

The ethical turn described in this paper calls for exploration of communication in order to undo conditions for 
annihilation of otherness. Levinas [1] observes that if the ethical is sought in fusion rather than in openness to alterity, a tragedy may take place once communication becomes a variation or reduplication of the Self and thereby establishes a monolog as an innate and natural form of communication. Genocides can be described as extreme cases of the tendency for reduplication of Self and annihilation of otherness. The challenge is how to retain responsibility towards the Other. How to view the relation among ethics, religion and social phenomena such as genocides? Are they instances of human inter communication?

The paper proposes to view communication not primarily as a transmission of thought or as means of expression of emotion and social status, but as a manifestation of the ethical. It explores the relation among social violence, communication and the ethical and proposes to overcome challenges in intercultural negotiations through an ethical turn in conceptualization of communication. The paper starts with an examination of inconsistencies in philosophical views on the relation among the ethical, theodicy, the third, mediatedness, and modernity. It continues with a re-evaluation of the information-based definition of communication and introduction of a new view on communication as manifestation of the ethical and ends with a discussion on factors that challenge and enhance the ethical in the context of genocides, specifically in relation to the on-going situation in Palestine and the genocidal processes it involves.

\section{Annihilation of Otherness and the Ethical}

Genocides are social phenomena [2-4], not individual criminal acts but biopolitical activities [5] against humanity as such [6]. Todorov [7: 99] gives a pointed example of the mechanisms leading to annihilation of otherness: When the Spaniards reached the shores of the New Continent at the end of $1400 \mathrm{AD}$ they shouted from the dock of their ship to the Natives' canoes: "What is the name of this land?” The Natives answered: Ma c'ubah than. The Spaniards heard "Yucatan" and concluded that this is the name of the province. The response of the Natives was taken as an answer already implied in the question; it merely mirrored what was already conceived. What the Spaniards did not suspect is that the meaning of the expression "Ma c'ubah than" in the local language is something like "We do not understand your language" or "Who are you". This meeting is a distilled metaphor of the meeting between sameness and otherness. In the initial meeting with the Other, the Spaniards extricated the foreign and placed it in a context furnished by their own knowledge of the world. They did not even suspect the possibility of any other response than an answer intended in their question. With the same strategy, they continued taking over and plundering the unknown continent, thus committing a horrific genocide and causing the death of 90 million Native Americans [7]. Unlike many other historical accounts, Todorov's describes with great intensity this specific historical point in which "violence enters the picture under the cloak of innocent ignorance" [8, p. 295]. The extinction of the indigenous civilization took many different forms and degrees of (ir)-responsibility: direct killing by gun, knife or other tools, by negligence, psychological torture and humiliation, taking over of homes, resources and lands, stealing, hitting and raping of wives and children, often in front of the humiliated husbands and fathers, spreading of diseases, instigating tribes against each other, etc.

This example illustrates the bond between ethics, communication and negotiation but it also indicates how ethics emerges through and in language: beyond the contents delivered and the linguistic structure it enforces, language inspires the fundamental response-ability between Self and Other. Responsibility implies both being response-able to the Other's call and being responsible for the Other, reaching out to alterity, beyond the Self. Communication transpiring between Self and Other(s) is not only exchange of information, or participation in a discursive sphere; it is also a manifestation of the fundamental responsibility to and for the Other. This is, according to Martin Buber [9,10] and Emmanuel Levinas [1,11], the origin of language and communication: openness, exposure, proximity, and responsibility. Response-ability or a priori agreement is not always representable linguistically, it is the fundamental relation and the condition for any understanding and representation. There are, however a few questions concerning Levinas' concepts of ethics, theodicy and rationality, which demand attention due to inconsistencies with his own and Buber's idea of the ethical.

\subsection{Is the End of Theodicy Also the End of the Ethical? The Ethical Is Beyond Theodicy, It Is "a Space of Profound Intimacy"}

There is an inconsistency in Levinas' view of theodicy, which confuses the relation between theodicy, genocide and the ethical. He motivates his call for faithfulness to Judaism on Emil Fackenheim's claim that in difference 
from other genocides the Nazi genocide of Jewish people is not rational (see above): "if God was absent in the extermination camps, the devil was very obviously present" [11, p. 84]. In other words, faithfulness to Judaism is motivated by the presence of evil, which is caused by the end of theodicy ${ }^{1}$. On one hand, Levinas notes the end of theodicy in Nazi concentration camps and on the other, he notices that the ethical "cannot, without becoming perverted, be made into a preachment" [11, p. 85]. However, if the ethical is beyond preachment then it is not dependent on theodicy. Theodicy served and still serves as a motivation of genocides and occupations, as "justification of the neighbor's pain", "the source of all inhumanity" (ibid.) whereas the ethical sensibility is, as Levinas puts it, "the most profound adventure of objectivity, its ultimate intimacy. But this intimacy can only be discretely" (ibid.). Similarly, Todorov and Denner [12] finds goodness in history occur discretely, in silence, as a most intimate action. Thus, end of theodicy is not the end of the ethical, which is a space beyond preachment, a space of profound intimacy. If so, uniform faithfulness to Judaism or other religious beliefs cannot assure the absence of evil and the ethical turn but it can close the space 'beyond preachment', the space beyond the Self and openness to otherness.

\subsection{Are Some Genocides Rational?}

Levinas' concept of the ethical is also informed by Fackenheim, who claims that some genocides are rational whereas others are not (as quoted in [11, p. 84]):

"The Nazi Genocide of the Jewish people has no precedent within Jewish history. Nor $\cdots$ will one find a precedent outside Jewish history $\cdots$. Even actual cases of genocide, however, still differ from the Nazi in at least two respects. Whole peoples have been killed for rational ends such as power, territory, wealth $\cdots$. The Nazi murder $\cdots$ was annihilation for the sake of annihilation, murder for the sake of murder, evil for the sake of evil."

It follows that according to Levinas and Fackenheim some genocides such as forceful taking over of folk's lives/habitat/territory, are rational and understandable, whereas others, such as genocidal purification of certain ethnic population or improvement of human population are not. However, whether we accept genocides as rational and understandable in cases of colonization and not in cases of ethnic annihilation in the face of immigrants or strangers or Others, we are still in the space of the unethical as both phenomena are extreme forms of non-openness to otherness.

\subsection{Can the Ethical Relation Be Mediated? "... This Intimacy Can Only Be Discretely"}

There is yet another inconsistency in Levinas' view of the ethical, which is not related to theodicy but to justice and mediation. To the question "Can an ethical relation be mediated by a Third party?" Levinas seems to answer both "yes" and "no" whereas for Buber the ethical is a priori and unmediated. In fact, Buber [10, p. 41] has another term for interaction through a Third, he calls it speechifying:

"By far the greater part of what is today called conversation among men would be more properly and precisely described as speechifying. In general, people do not really speak to one another, but each, although turned to the other, really speaks to a fictitious court of appeal whose life consists of nothing but listening to him."

Buber formulates the ethical in relational and communication terms as an I-Thou relation between Self and Other and the unethical as an I-It relation. The I-Thou relation is characterized by openness to the Other and absence of imposition, whereas the I-It relation is closed to Otherness and therefore breathes on imposition. Since the ethical is defined in relational terms the issue of mediation is connected to the concept of mutuality in relations, which is crucial for Levinas' critique of Buber. For Buber, full mutuality is not characteristic of human relations but readiness for it is a manifestation of the ethical: "From your own glance, day by day, into the eyes which look out in estrangement of your 'neighbor' who nevertheless does need you, to the melancholy of holy men who time and again vainly offered the great gift - everything tells you that full mutuality is not inherent in men's life together. It is a grace, for which one must always be ready and which one never gains as an assured possession" [10, p. 121]. Thus, for Buber mutuality is not a condition for an I-Thou relation i.e. for the ethical.

${ }^{1}$ This argument is cyclic because the idea of evil is theodal. 
In Levinas', interpretation, however, the I-Thou relation is possible only through full mutuality but since it can't be assured the involvement of the Third is necessary. He calls that the birth of Justice. However, as the Third gets involved, the possibility for the ethical is diminished because the I-Thou relation is a priori accepted and thus unmediated.

For both Buber and Levinas the ethical I-Thou relation is in essence unmediated, "the most profound adventure of objectivity, its ultimate intimacy. But this intimacy can only be discretely $\cdots$. It cannot, without becoming perverted, be made into a preachment” [11, p. 85]. This view is consistent with Buber who does not postulate mutuality in the I-Thou relation but it is inconsistent with Levinas' idea of the Third mediating the I-Thou relation. If full mutuality is a necessary condition for an ethical relation and since the Third or justice doesn't bring mutuality into the ethical relation, it can't bring about the ethical either. Hence, justice and the ethical are not the same, nor are they reciprocally related. Furthermore, if mutuality is a necessary condition for the I-Thou relation, so it is for the I-It relation. The Third can mediate the I-It relation but can't therefore bring about an I-Thou relation. Even if the I-It relation is mutual it is still not a manifestation of the ethical. Thus, mutuality cannot be a necessary condition for the ethical.

\subsection{Are Genocides Products of Modernity?}

Both Bauman [13] and Arendt [6] see a causal connection between modernity and genocide:

"I propose to treat the Holocaust as a rare, yet significant and reliable, test of the hidden possibilities of modern society [13, p. 12].”

"The frightening coincidence of the modern population explosion with the discovery of technical devices that, through automation, will make large sections of the population 'superfluous' even in terms of labour, and that, through nuclear energy, make it possible to deal with this twofold threat by the use of instruments beside which Hitler's gassing installations look like an evil child' fumbling toys, should be enough to make us tremble [6, p. 99].”

However, genocides occurred throughout human history and are not specific to modernity. The so called Spanish 'conquest' of Mexico at the end of 1400s is an example of a genocide, in which 90 million indigenous individuals and folks were killed with varying levels of responsibility [7]. The European colonization of America, Australia and New Zeeland resulted in the extinction of indigenous humans and peoples. The Ottoman Empire's massacres targeted folk groups, such as Armenians and Bulgarians. The Spanish colonization of Bolivia aimed at enslavement and extinction of the local indigenous population. In South Africa, the Dutch and British immigrants designed the apartheid, yet another form of genocide. Thus, genocides are not products of modernity as such but they are assisted by modern biopolitics:

"The novelty of modern biopolitics lies in the fact that the biological given is as such immediately political $\cdots$. When life and politics - originally divided, and linked together by means of the no-man'a-land of the state of exception that is inhabited by bare life-begin to become one, all life becomes sacred (i.e. not worth sacrificing, BM) and all politics becomes the exception [5, p. 148].”

According to Agamben, what is specific for modern societies, which generate genocide is the identification between biological life and politics (i.e. political interests such as power, territory and wealth, etc). However, even in the Middle Ages, Indigenous Indians’ biological life was not subject to ethics nor sacrifice unless they converted to Christianity, but their land, society and territory were not spared even by theodicy.

\section{Communication as Manifestation of the Ethical}

Similar to Bauman and Arendt, Peters [14] sees modernity, including Weber-like bureaucracy and technology as potentially growing fields for future genocides. However, he finds the explanation for this potentiality not in technology and modernity per se but in the historicity of the concept of communication. He points out (ibid.) that for the past 60 years the humanities have been dominated by a metaphor of communication borrowed from telephony. Historically, the modern concept of communication is a product of a dream for instantaneous connection or a nightmare of being locked in a labyrinth of solitude (ibid.). Consequently, the modern concept and idea of communication is locked in this dichotomy, which dislocates our attention from the ethical nature of commu- 
nication. Application of the telephony metaphor to human interaction leads to intolerance to interpersonal differences i.e. decreased openness to otherness. The following subsections further Peters' critique of the definition of interhuman communication as a transmission of information and develop the idea of communication as a manifestation of the ethical.

\subsection{Re-Evaluation of the Definition of Communication as Exchange of Information}

The question "when did we start using the word communication as we do today" brings us, according to Peters (ibid.) to the First and the Second World Wars. Technological development during, before and after the wars aimed at satisfying war purposes, one of which was communication between military units, especially secret and immediate transfer of information. At the end of the war, Claude Shannon [15], scientist at Bell Telephone Company, formulated his mathematical theory of signal transmission aiming at maximum telephonic line capacity with minimum distortion. According to this model, a message begins at an information source, which is relayed through a transmitter and then sent via a signal towards the receiver. Before it reaches the receiver, the message goes through noise or sources of interference. Finally, the receiver conveys the message to its destination. Thus the purpose of this communication model is to reduce noise and to make input as similar as possible to the output, despite inevitability of interference. Noise or interference is treated as an essential but undesirable condition of communication. Within this model, there are few very important technical concepts that need to be mentioned:

- Information as a technical term is defined as a measure of one's freedom of choice in selecting a message; information is what is carried by the signal (sent by source) and received by the receiver (and destination);

- Uncertainty: the more uncertainty there is the least information there is i.e. if there is no information then there is no communication;

- Predictability: the more predictable a part of a signal is the least freedom of choice there is. The more predictable a signal is the least uncertain it is and the least information it carries;

- Noises are conditions, which work against predictability;

- Redundancy is the opposite of information but works against noise;

- Efficiency: the more bits of information are sent and received the more efficient the communication is;

- Accuracy: the clearer the reception is the more information can go through;

- Fidelity is the degree of sameness between the transmitted and the received.

These concepts and Shannon's model of signal transmission were applicable first within mathematics and informatics. However, Peters emphasizes that Warren Weaver, Shannon's co-writer and a physicist at the Ford Foundation at that time, extended the meaning of communication and all the associated with it concepts listed above beyond their technological origin [as cited in 14, p. 24-5]:

"The word communication will be used here in a very broad sense to include all the procedures by which one mind may affect another. This, of course, involves not only written and oral speech, but also, music, the pictorial arts, the theater, the ballet, and in fact all human behavior. In some connections it may be desirable to use a still broader definition of communication, namely, one which would include the procedures by means of which one mechanism (say automatic equipment to track an airplane and compute its probable future positions) affect another mechanism (say a guided missile chasing this airplane).”

This metaphorical extension applied the telephonic concept of information transfer and information loss to interpersonal cognitive/emotive communication. It became an adequate description of the relation between a spectator and a ballet dancer, between a ballet dancer and his/her art, between a speaker and a listener, a missile and a target. Studies on the model of Shannon and Weaver took two major directions. One applied the engineering principles of transmission and perception within electronic sciences, the other explored interactant's ability or inability to communicate. The communication-as-a-transmission metaphor continues to dominate studies within informatics, interaction design, linguistics, literary theory, art theory, communication studies, ethics, etc. Within cognitive psychology, Johnson-Laird [16] described language communication as a process where a sender intentionally produces signal to convey information to a receiver $\cdots$ " and modify the behavior of the reactor”, added Krebs \& Davies's behavior ecology [17], to which Ogden \& Richards [18] had contributed one more word: "successfully”. Even within neuro-psychology, Kimura [19] applied the same model: interspecies' communication is when one member of the species conveys info to another member of the species. 
Peters’ [14, p. 25] comment observes certain tendencies in Weaver’s metaphor:

“An extraordinary category, this, including music and missiles, speech and servomechanism … Both the bomb and information cater to a secret pleasure in possible apocalypse, the exhilaration moderns (so used to the thrill of the new) feel in contemplating self-destruction.”

The definition of communication is no longer a lexicographer's problem; it encapsulates the breathless resolution with which the post-war or post-traumatic industrialization rushed to build a common ground for non-conflict societies, namely, through more and better “communication”, including language, missiles and art. According to this model, the more one repeats the same thing the more likely it is that the listener will understand it correctly. Creativity on the part of the receiver becomes unwanted noise; poetic and phatic functions, spiritual language, puns, etc. become communication with noise.

The idea that all thoughts, memories, ideas etc., which do not fit the intended meaning are responsible for loss of information and are interpreted as distortion eliminates the right of existence of otherness, the significance of surprise. It follows that if there is a misunderstanding the transmission has not happened i.e. communication has not been successful, has not occurred. Communication becomes either destructive or therapeutic, its main function is to eliminate or cure us from our differences i.e. from our Selves and Others.

The concept of predictability points out a paradox in the model, namely that communication is successful when noise is eliminated. In the same spirit, the model desires predictability. However, the more predictable something is the less information it carries, the less information it carries the less communication there is. In effect, the more unpredictable something is the more information it carries and the more communication it stimulates.

Peters notices that Weaver's metaphor infiltrated even incommunicable, the dead and extra-terrestrials become part of it. When lack of common ground is an acceptable motivation for wars and violence

“... the despair felt at the impossibility of communication $\cdots$ marks the limits of all pity, generosity and love

$\cdots$. But if communication bears the mark of failure or inauthenticity in this way, it is because it is sought in fusion [1, p. 164].”

The fusion sought on conceptual, linguistic, social, ideological, political, and emotional levels is triggered by the communication-as-combat-against-noise (or interruption) metaphor. This tendency towards sameness, caused by and resulting in irrational fear of otherness builds on the temptation to reduplicate the Self, to mirror signal/meaning/ideas. Who and/or what is reduplicated becomes a matter of power. Communication as exchange of information corresponds to the economy of exchange, including the circulation that involves reprisal, returning blow for blow, settling scores, and vengeance. Jacque Derrida [20] criticized the symmetry between debtor and lender, offender and offended, sender and receiver by pointing out the differences, the arbitrary semantic and institutional constructs that impose rather than reflect order. Thus communication as reduplication of the self crashes, causing pain and remorse, which later translate into further repetition, reduplication, despotic reciprocity, and projection of the Self.

\subsection{Communication as Tension between Reproduction of Self and Reconciliation with Alterity}

Locked within a dichotomy in conceptualization of communication “at once a bridge and a chasm” [14, p. 5], “dream of instantaneous access and a nightmare of the labyrinth of solitude”, telepathy and solipsism, telephony and poesis, missiles and swan lakes, we miss the opportunity to meet the Other and the Self. Instead of viewing human communication as a battle against noise for a clear message or as a therapeutic technique, we can view communication as an ethical process, as an opportunity to meet otherness, outside or inside the Self. The emerging truth is as Peters’ [14, p. 21] puts it:

"Communication as reduplication of the self or its thoughts in the Other needs to crash for the resulting discovery of the Other (besides knowing and the check on the hubris of the ego) is in essence the way to the distinctness of human beings.”

Human history is sprinkled with such crashes (e.g. [7]) with or without the discovery of the Other although it is this discovery, which permits and organizes life. Inspired by Ralph Waldo Emerson, William James, Adorno, 
and Buber, Peters [14, p. 31] offers a new definition of communication as reconciliation with Alterity:

"The most wonderful thing about our contact with each other is its free dissemination, not its anguished communion $\cdots$ acknowledging the splendid otherness of all creatures that share our world without bemoaning our impotence to tap their interiority.”

In the same vein, the ethical turn calls for a re-evaluation of "miscommunication". A failure in communication, i.e., misunderstanding, interruption and disturbance, do not necessarily denote an ethical failure. To the contrary: if language is seen as a tool with which one might reduce the difference between Self and Other, then such failure is precisely what opens up the very possibility for ethics. It is in the unsettling moment of incomprehensibility that one is exposed to the Other's otherness with no guidance as to how to respond.

\section{Empathy and Reconciliation with Otherness}

It is claimed that empathy plays a key role in the development of harmonious individuals and societies [21-23] and its absence is characteristic of genocides. Empathy has been defined as a process and a capacity to take the role of the other and to adopt alternative perspectives vis-à-vis oneself [21] or the intellectual or imaginative apprehension of another's condition or state of mind [22]. Lack of empathy is linked to anti-communal behavior [24] and attitudes. Empathy is identified with interactive behavior such as empathic listening [25] openness, paraphrasing, and reflection and is considered to be an important negotiation skill [26].

If communication is defined as reconciliation with otherness then how does that affect conceptualization of empathy? Empathy is a result of a distinction between Self and Other, which invites the ethical. If communication, part of which is empathy, is defined as exchange of information then empathic adoption of the other's view is a form of transfer of data from Other to Self, a form of reduplication. However, if we have no immediate or telepathic access to the Other's feelings we can only imagine how they feel if we imagine how we feel or could or should feel in similar situations [27-30]. Thus, although, empathy is defined as an identification with the Other based on imitation, simulation or representation, as a way of reaching alterity, it is stamped by the viewers perspective on communication: it is either a mirror in the labyrinth of solitude or a magical realization of the dream of instantaneous access. In both cases, empathy is an effort for fusion, which for Levinas' causes failure in communication and thus it is a call for ethics not less than a misunderstanding. It is hard to imagine empathy being the end of "all pity, generosity and love" because it is most commonly defined as the manifestation of the later. However, empathy may give a false sense of understanding of the Other and thus mark unnoticed breakdown in communication. This is the case when demonstration of empathy is used as a technique that aims at agreement or communion in a rather unauthentic manner [29]. At the same time, failures in empathic exchange, as in the case of refusal and rejection of empathy, similar to 'failures' in communication, are, in Levinas' terms, calls for ethics, invitations to face the otherness of the Other because it is in the moment of miscommunication that we have an opportunity to meet the alterity i.e. to communicate.

\section{Potential for Negotiation and Reconciliation}

The ethical turn in history, business and society through reconceptualization of communication as reconciliation with otherness offers a potential for negotiation. This section discusses social and conceptual phenomena that condition enhancement or challenge the ethical turn.

\subsection{Challenges}

The redirection of attention on communication as manifestation of the ethical is blocked by social and individual phenomena, which sustain the established order. Some of these stand out as particularly counter-productive to the ethical turn, namely: the patriarchal order, dehumanization procedures, implantations by the Third, non-acknowledgement of the larger context, and the traumatic disorders and state of denial of the populations in question.

\subsubsection{Patriarchal Order}

No matter what political and social order there is capitalism, socialism, kingdoms, republics, etc., contempo- 
rary humanity has one common overall order, namely patriarchy, which stands responsible for social violence and domination [31]. This order is kept in contact by repetitive communicative patterns, including violation of bare life, social and human rights of women and children in patriarchal conflicts. In some cases, women and children are simply victims, in others-they are raised to support the patriarchal order in various ways e.g. by joining armies. In either case, women become sexual victims of all sides in a conflict [ibid.]. Rapports on brutality and violence against women and children gathered by Erturk and other special rapporteurs of the United Nations, including brutality against women and children in Palestine, point out the omnipresent patriarchal order as one of the major challenges to communication as manifestation of the ethical.

\subsubsection{Dehumanization}

Dehumanization before, during and after genocides and conflicts takes different forms. Bureaucracies of different kinds had dehumanizing effects, which brought out conflicts. For example, the strict colonial Belgian administration's ID card classification files in Rwanda, which gave out each person's ethnicity and number or the IBM contribution to the development of the meticulous numerical Nazi classification of victims. Another example of dehumanization as a manner of obliteration of communication is described by Sari Hanafi [32]: walls separating Israeli and Palestinian land depict empty landscapes on the Israeli side, erasing the buildings and people behind them. Israeli neighbors can see only uninhabited landscapes i.e. open resources. Since contact across the boarders is associated with unpleasant military check-ups, Hanafi witnesses that people living on the Palestinian side of these agoraphobic walls live for months and years without any interaction with their neighbors i.e. the people on the Israeli side of the wall, who, having not even a visual contact with their neighbors, abstract their existence. As expected, this visual dehumanization or invisible otherness results in literal cancellation of communication. Turning the Other into a number or eliminating her from the visible landscape is an challenge to communication as manifestation of the ethical because otherness is in these cases obliterated, removed, or erased.

\subsubsection{The Third}

Buber's view of the non-mediated character of the ethical relation (see 2.2 above) finds support in history. For instance, the genocidal conflict in Rwanda was instigated by Hutu expatriates, some of them broadcasting on radio from abroad [33]. Thus, speechifying and involvement of the Third may result in lack of immediate and authentic contact between people/groups and contribute to the abstraction of the conflict, which may transform into dehumanization and brutality.

Media can function as a channel for the involvement of the Third. For example, the organization 'If Americans Knew' counts the way US media report deaths in the Israeli-Palestine Conflict and show that media under-represent Palestinian losses and over-report Israeli losses. Thus media can instigate conflicts and bring about denial but not because of compassion/media fatigue. For Cohen desensitization is an urban myth' because the issue is "media's framework of reporting, rather than the public's capacity to keep absorbing” (34, p. 192) and because "denial cannot result merely from familiarity and repetition". There is no "compassion fatigue but rather compassion avoidance. The audience $\cdots$ looked away $\cdots$. This is the essence of denial and bystanding: an active looking away, a sense of a situation so utterly hopeless and incomprehensible that we cannot bear to think about it. $\cdots$ There is, after all no, such things as love fatigue. And most parents do not become numbed or oblivious to their child's pain and suffering however often she bumps her head or cries $\cdots$. Repetition just increases the sense of their remoteness from our lives" [34: 193-4].

This inauthenticity of relation, embedded in a sensationalist and entertainment language, "any dimming of compassion, any decreased concern about distant others" [34, p. 195] is according to Cohen not just a result of fusion, of reduplication of Self in the image of the Other, as in Levinas, but "is just what the individual spirit of the global market wants to encourage" (ibid.). Thus, for Cohen, the global market economy creates conditions for dimming response-ability between Self and the Other, discouraging communication as manifestation of the ethical i.e. challenging I and Thou relations by forceful mediation of the Third.

\subsubsection{Larger Context}

As Dona [33] points out, genocides cannot be analyzed outside of their contexts, they are embedded in other types of conflicts. For instance, in Rwanda, Belgian colonial interest and the World Bank were pushing structural adjustments, triggering economical hardship, changes in the price of natural resources such as tea. The context 
of the Nazi genocide is WWII and the context of WWII is the economic and political hardship in Germany after WWI. In the Middle East we have a complex international situation striving for control over human and natural resources. The gradual and spatial genocide of the Palestinian people is embedded in a larger international conflict and in a religious context, which influence and direct it as a third party.

\subsubsection{Sources of Brutality}

Milgram [2] and Haney et al. [4] found that brutality is a social phenomenon that it is born by association with certain social roles. However, it can also result of neurological and psychological states of individuals. As genocides are embedded in larger conflicts, life and the ethical after and during but also before the genocide are challenged by physiological, neurological, psychological, and social changes:

"Some form of normalization is integral to narratives of suffering and atrocities. Perpetrators, victims and bystanders can indeed 'normalize' in the sense of 'get used to the most unimaginable horrors $\cdots$. And even of constant exposure to horror images leaves TV viewers in a state of mental inertia, this results more from a sense of helplessness than a perception that everything is just as it should be [34].”

Survivors from both sides suffer from a diversity of illnesses and disorders, such as post-traumatic stress disorder, which express as changes in the morphology of the brain [35]. Empathy and care for the Other are thus challenged even on a neurological level $[23,36]$. It is only natural that reorganization and life during but also after genocides are difficult and sometimes impossible within the same generation. Many indigenous people in Mexico [7], Hutu genocide survivors [33], Indigenous Americans from USA and Canada [34], and WWII genocide survivors committed suicides or live/d with self-destructive patterns of behavior [36,37].

Characteristic of societies and individuals involved in a genocide is the state of denial. The neurological traumas can explain diminished ability to feel and act with empathy or to communicate, which is associated with compensatory coping mechanisms such as denial describe well by Cohen [34, p. 158]:

"The Israeli culture of denial does not derive from state communism or military dictatorship $\cdots$. But denial of the injustices and injuries inflicted on the Palestinians is built into the social fabric $\cdots$. Israel is a country of 'open secrets'. Even those known to the whole world, like existence of Israel's nuclear capacity, are protected with bizarre tenacity. Official lies are uttered with a straight face, and received with a knowing wink $\cdots$. Unreflected attachment to pious kitsch of Zionism and its myths such as 'purity of arms' '... Jews have defensive self-image and a character armour of insecurity and permanent victimhood $\cdots$ exclusion of Palestinians from a shared moral universe and an obsessional self-absorption: what we do to them is less important than what this does to us. The close interpenetration between civilian and military life (an army drawn largely from universal conscripts and reservists) means that the public is less an 'audience' then a reliable source form confirming common neutralizations $\cdots$. Perpetrators can always assume populist vindication $\cdots$ on the 19 and 21 January 1988, Israeli soldiers entered the two West Bank villages of Hawara and Beita. The orders were quite clear-though, since their origin in Defence Minister Rabin's instructions to 'break the bones' of suspected rioters, they had been relayed with ambiguity and deniability. The soldiers (using a security service list) pulled twenty young Palestinian men from their homes, took them to nearby fields, gagged them, tied up their legs and arms, then threw them on the ground. They then implemented Rabin's orders: with clubs, stones and by hand, they systemathically broke the arms and legs of each Palestinian except for on whom they left able to walk for help. A military bus was left running in the background, revved up by the driver throughout to muffle the screams $\cdots$. There was much attention to the nightmares and traumas of the soldiers; the victims were never mentioned again. On 5 February, within a few weeks of this incident, a group of Israeli soldiers entered the village of Kafr Salem, arrested four Palestinian youths, beat them with clubs, and then ordered an army driver to run them over with his bulldozer. He refused, but instead shoveled earth and garbage over them until they were almost completely covered and buried alive $\cdots$. The overwhelming public reaction was sympathy for the four soldiers who were arrested. 'I am not ashamed of what I did, but what they are doing to me hurts'.”

Collective and individual pathological states of denial like those described by Cohen above are often associated with social fixations therefore psychological disorders and neurological dysfunctions are serious challenges to the ethical and generational insights and specialized treatments, necessary. 


\subsection{Enhancers}

Manifestation of the ethical such as openness to otherness is enhanced by a number of phenomena, actions and activities, which promote negotiation. The next subsections elaborate on how intercultural communication, hybrid cultures, local traditions of co-existence, and distance taking in time, topic, and emotion open assist the ethical turn.

\subsubsection{Intercultural Communication}

Todorov's account of the history of Yucatan is a clear example of the tragic effects of unethical intercultural communication, realized firstly as linguistic and discursive assumptions of similarity. Although Palestinians and Jews have common history their communication is intercultural also because the Jews who immigrate Israel after WWII represent many different cultures. The larger context of their generally but not only violent interaction is the relation between Arab countries and the NATO, which is another instance of intercultural communication. There are diverse views on the effects of intercultural communication. Iles [38] finds that it aggravates relational conflict. "Culture is more often a source of conflict than of synergy. Cultural differences are a nuisance at best and often a disaster [39]."

Enayati [40] emphasizes its potential for enhanced performance and creativity yet there are not so many studies of intercultural communication as cross-cultural studies predominate the field. The cross-cultural perspective studies behaviors, values, norms, and perceptions of one culture in mono-cultural conditions and in comparison to those in another culture [39]. Intercultural studies examine behaviors, values, norms, and perceptions of participants representing different cultures in intercultural settings. Most "findings" in the intercultural communication field are cross-cultural and oriented towards description of similarities and differences [41] such as:

- In difference from USA, Mexico, Iran prefer leaders responsive to group norms;

- Collective cultures prefer charismatic leaders;

- Individual cultures prefer task-oriented leaders;

- High Power Distance prefer directive leadership;

- In Japan turn-taking is characterized by pauses, in USA by latching and in Brazil - by overlap.

There are only a few pure intercultural negotiation behavior studies. Reeh et al. [42] finds nonverbal reciprocal adaptation [43] in intercultural conditions, which is not observed in mono-cultural conditions. Qui \& Wang [44] find verbal reciprocal adaptation in negotiation role-play between Chinese and Swedish women.

- Bargaining-gravitating towards each others' value

- Mirroring, imitation

- Drop learned own cultural behaviors

Gumperz [43, p. 13] defines reciprocal adaptation in the following way: "The procedure is one of reciprocal adaptation, where each participant gradually learns to adapt and to enter into the other's frame of reference.” Thus if cross-cultural studies compare cultures in their intracultural functionality and find or predict similarities and differences, in intercultural conditions we observe a process of mutual adaptation, of reciprocal reaching towards each other, which along with exposure to otherness produces hybrid cultures.

Intercultural communication and negotiation involve and bring adaptation as a reaction to the exposure to otherness, which manifests the tension between a desire for fusion, for reduplication of self and a possibility for reconciliation with otherness, for openness to the unknown. Reciprocal adaptation in a climate of violence is as bad as invisibility and dehumanization but whereas dehumanized walls promote conflict the exposure to otherness opens a possibility for communication as manifestation of the ethical. This demands future reevaluation of intercultural communication training material ad conceptualization.

\subsubsection{Nurture Hybrid Cultures}

Intercultural communication stimulates hybrid cultures, which are characterized by inclusive norms and flexibility [45]. Dona [33] finds that during the genocide in Rwanda there was what she called "invisible majority” i.e. people who are not part of a conflict and therefore invisible. Out of approximately 7 million population in Rwanda, 85\% were Hutus, 12\% - 13\% were Tutsi and 1\% - 2\% - Twa (the indigenous population of the area, Hutus' are migrants to Rwanda). There were 200,000 perpetrators, 1 million people were killed victims, half of whom are Tutsi, plus many sympathizing to them Hutus, and 1.3 million did not kill but supported the genocide in some way. Dona concludes that what remain are 4 million people with no agency, the so called invisible ma- 
jority, they were neither perpetrators, nor victims, nor sympathizers, nor anti-patizers. Who are these people? Why are they kept invisible, unheard? Dona found that many of these people were ethnically hybrid i.e. with mixed ethnicity. They showed more flexible communicative and action skills in the conflict. Thus, nurturing hybrid cultures and carriers of hybrid cultural values hinders social fixations and opens possibility for communication as a meeting of otherness.

\subsubsection{You and I, Rather than You or I}

In the process of realization of genocides, including what Hanafi calls spaciocides, occur also exceptional events and instances of behavior, which are not in accord with horror. During the Spanish "conquest" of the lands and folks called today Mexico, some offenders protected victims [7]. In Rwanda, some Hutus gave food to Tutsi kindergardens and warned of attacks [33]. In South Africa, some guards broke orders and talked with compassion to political prisoners or gave clothes to birth giving prisoners [46]. Some Nazis tried to help prisoners [6]. In Bulgaria, no Jew was send to a concentration camp and there were more Jews after the Second World War then before. These exceptional phenomena manifest both human frailty and promote the ethical.

Genocides interrupt periods of time when people/s live in peace. Before the Belgian occupation Hutus and Tutsis lived side by side for centuries, through migrations, peace, and conflicts. Before the genocide Jews, Gypsies, Poles and locals lived in peace together in Germany, Hungary, Italy. The indigenous people in Mexico, Africa and the Americas lived through local wars but no genocides. Before the establishment of Israel in 1948 Palestinians and Jews shared land and life. Before the war in former Yugoslavia Serbs, Croats, Bosnians, Albanians, Macedonians, etc. lived side by side. Thus, peoples involved in genocide have local knowledge and experience in generational maintenance of peace, which has been interrupted, but can be studied, traced and utilized.

Exceptions are manifested also in the fact that there is an invisible majority, which is not part of genocide (see 5.2.2). For instance, in Rwanda, the majority of the population was neither victims of genocide nor perpetrators [33]. This motivates Dona [ibid.] to call for a change of terminology: rather than describing ethnic violence it is more adequate to talk about social relations during violence. The advantage of this reformulation is the displacement of attention from the horror and the enlargement of the context of life. The disadvantage is the normalization [34] of occupational violence, which transforms into genocide.

\subsubsection{Consequences and No Consequences}

In most cases there are no punitive consequences for the violators: in Mexico, we have assimilation of the indigenous survivors with a Spanish rule; in USA, Canada and Australia the survivors live in reservation camps after occupation; the New Zeeland colonial government offered an apology to the surviving indigenous people no other consequences for violations against humanity; in Bolivia and South Africa the indigenous survivors accomplished a majority representation in the government; Armenia, Bulgaria and Israel established sovereign states. The Jewish survivors required the establishment of the sovereign state of Israel and took judicial action against the violators as a state. Urged by the international and local community, Germany held courts against violators of humanity. Although genocide was formulated as violation against humanity, which makes these violations subject for international courts, prisoners such as Eichmann were not released and were tried in national courts of Israel. The Jerusalem proceedings, however, violated requirements of justice as 'the court did not admit witnesses for the defence' [6, p. 101] and were therefore more symbolic in character than judicially just. In contrast, Rwanda is going through a peaceful reconciliation process, which is not revengeful in character but nevertheless painful. Awareness and evaluation of facts and consequences is of major importance in communication not in terms of revenge and justice but in terms of the possibility for the ethical.

\subsubsection{Distance Taking}

Openness to otherness as altruistic behavior can be described as a distance taking from own purposes, which does not mean sacrifice but rather adaptation and transformation of own purposes.

\subsection{Time Distance}

Jens Agerström [47] finds tendency towards increasingly moral decisions in distant future and greater moral blame attributed to distant future actions. Future altruistic behavior is perceived as more praiseworthy than near future altruistic behavior or quick winning. It is thus more likely to commit to altruistic behavior when thinking 
about distant vs. near future events. This is explained by Construal Level Theory [48] according to which the future is represented at a higher, more abstract level of mental construal than the near future and high-level mental construals shift attention to core values and higher-order principles. Various linguistics expressions manifest this insight even in folk psychology, such as, "widen your views", "open old wounds” vs "heal”, "break away from old habits", "see a forest not a tree", "lift your gaze from everyday routines", "locked behind the bars of prejudice and narrow-mindedness", etc.

A good example of the idea that "moral concerns loom larger in the distance of future" [47] is Begin's emotional agreement at Camp David 1978 upon receiving Carter's signed photos dedicated to Begin's grandchildren. Thagard [49] describes that the emotion triggered by this gift and mention of Begin's grandchildren is responsible for his unexpected agreement despite two weeks of disagreements and a near stale mate situation at Camp David. In the context of Construal Level Theory, Begin's grandchildren represented a distant future in a personal dimension and this future perspective inspired personal involvement, altruism and agreeability.

\subsection{Shift of Topic/Attention}

Another technique for opening to otherness i.e. of shifting attention to the other and transformation of own purposes is topic-shift and recontextualization. Martinovski [50,51] examines a plea bargain, which ends up in a stale mate where none of the parties is willing to give in. This is followed by a relatively long silence and a shift of topic, away from the issue at hand. For the sake of clarity, I will quote the transcription here:

$221(0.8)$

222 ( ): ((throat clear) $=$

223 Jge: = what do you think would be reasonable. Jerry,

224 (6.0) (sound of turning papers throught))

225 Jge: Do I hear it raining again? Is it [( )]

226 Def: [ ${ }^{\circ} \mathrm{Oh}$ my] god.

$227(1.2)$

228 (D): $\mathrm{h}[\mathrm{h}$

229 Jge: [I think that's rain [isn' it?

230 Def: [It only does it for spite.

$231(0.5)$

232 Prs: I think it is too.=

233 Def: = The sui's made of sugar. $<$ It melt[s.

234 Prs: [() out of (.)

235 of (0.7) top on it. 'It's a firebird. It's a- (0.5) ((clicking

236 sound: chair?)) ( ).

237 ( ): ((audible breathing))

238 (J): "hhh

239 Prs: Is a seventy five dollar (fine)?

240 Jge: Hh Heh huh. 'hh-

241 Def: Why don't we compromise and make it fifty.

242 Prs: That's done.

243 Def: Ar[ri(h)ght.]

The participants shift mental attention from the issue at stake (fight in court or a fee) to a larger context that they share (rain in dry Los Angeles, lines 225-236). This shift re-frames personal and professional goals, values, and preferences, which ends in a sense of a collaborative resolution (a sudden agreement on a solution of the case and even on the amount of the fee, lines 238-243).

\subsection{Art and the State of Awe as Universal Emotion-Cognitive Shifters}

Poetry, music, dance, painting, sculpture, and theater are ancient techniques for cognitive and emotional distance taking, shifting of attention from survival to transcendence, widening of views and lifting the gaze from the immediate, for giving new perspectives and restructuring old ones. Emotional states of awe are found to enhance sharing and cooperation. Maemura \& Horita [52] find that laughter and humor improve cohesion in restructuring, 
signal cooperation, promote connectedness and coping, and release tension.

\section{Conclusion}

This paper argues for an ethical turn in the conceptualization of communication. It re-evaluates Weaver's metaphor on communication as exchanges of information and develops Buber's and Peters' ideas on communication as manifestation of the ethical, where the ethical is described as openness to otherness and communication is viewed as a tension between reproduction of Self and reconciliation with alterity. It argues that mutuality is not a necessary condition for the ethical because it involves intimacy that can only be discrete, and that end of theodicy is not the end of the ethical because the ethical is a space of profound intimacy, beyond preachment. Extreme cases of annihilation of otherness such as genocides in all their stages and variations, can't be described as rational in some cases than others and have deeper roots than modernity. The ethical turn within socio-political conflicts, including the forceful take-over of Palestine and the genocidal process it involves, meets challenges such as the patriarchal order, implantations and involvement of the Third, dehumanization, isolation for larger contexts, traumatic disorders, and states of denial. However, the potential of communication as reconciliation is enhanced by insights in intercultural communication, nurturing of hybrid cultures, and distance taking techniques such as time distance, attention/topic shift, emotions such as feelings of awe and art.

\section{Acknowledgements}

I am grateful to Amer Obeidi and Melvin Shakun for rich conversations on the Israeli-Palestinian conflict. This paper is dedicated to the bright memory of my lovely friend Jeanette Katz, who survived the Holocaust to bring insight with a caress.

\section{References}

[1] Levinas, E. (1947/1989) The other in Proust. In: Hand, S., Ed., The Levinas Reader, Blackwell, Oxford.

[2] Milgram, S. (1971) The individual in a social world. Addison and Wesley, Reading.

[3] Milgram, S. (1974) Obedience to authority: An experimental view. Tavistock, London.

[4] Haney, C., Banks, C. and Zimbardo, P. (1973) Interpersonal dynamics in a simulated prison. International Journal of Criminology and Penology, 1, 69-97.

[5] Agamben, G. (1998) Homo Sacer. Sovereign power and bare life. Stanford University Press, Stanford.

[6] Arendt, H. (1963/1992) Eichmann and the Holocaust. Penguin Books, New York.

[7] Todorov, T. (1984) The conquest of America. The question of the other. Harper and Row, New York.

[8] Pinchevski, A. (2003) Interruption and alterity: Dislocating communication. PhD Thesis in Communication, McGill University.

[9] Buber, M. (2000) I and thou. Charles Scribner's Sons, New York.

[10] Buber, M. (1995) Det mellanmänskliga. (Element of the Interhuman). Dualis Förlag AB, Falum.

[11] Levinas, E. (2006) Entre nous. Thinking-of-the-other. Continuum, New York.

[12] Todorov, T. and Denner, A. (2001) The fragility of goodness: Why Bulgaria's Jews survived the holocaust. Princeton University Press, Princeton.

[13] Bauman, Z. (2000) Modernity and the holocaust. Cornell University Press, New York.

[14] Peters, J.D. (1999) Speaking into the air. Chicago University Press, Chicago. http://dx.doi.org/10.7208/chicago/9780226922638.001.0001

[15] Shannon, C. and Weaver, W. (1964) The mathematical theory of communication. The University of Illinois Press, Urbana.

[16] Johnson-Laird, P.N. (1990) Introduction: What is communication? In: Mellor, D.H., Ed., Ways of Communicating, Cambridge University Press, Cambridge, 1-13.

[17] Krebs, J.R. and Davies, H.B. (1978) Behavioural ecology: An evolutionary approach. Blackwell, Oxford.

[18] Ogden, C.K. and Richards, I.A. (1923) The meaning of meaning. Routledge \& Kegan Paul, London.

[19] Kimura, D. (1993) Neuromotor mechanisms in human communication. Oxford University Press, New York. 
http://dx.doi.org/10.1093/acprof:oso/9780195054927.001.0001

[20] Derrida, J. (1982) Margins of philosophy. Transl. Bass A. University of Chicago Press, Chicago.

[21] Mead, G.H. (1993) Mind, self, and society. University of Chicago Press, Chicago.

[22] Hogan, R.T. (1969) Development of an empathy scale. Journal of Consulting Psychology, 33, 307-316.

[23] Huther, G. (2006) The compassionate brain. How empathy creates intelligence. Trumpeter, Boston \& London.

[24] Eysenck, S.B.G. (1981) Impulsive and antisocial behavior in children. Current Psychological Research, 1, 31-37.

[25] Salem, R. (1982) Community dispute resolution through outside intervention. Peace and Change Journal, 8, 91-104.

[26] Toris, C. (1994) A negotiation model of empathy. 9th International Balint Federation Congress, Charleston, 9-13 November 1994.

[27] Stich, S. and Nichols, S. (1992) Folk psychology: Simulation or tacit theory? Mind and Language, 7, 35-71.

[28] Martinovski, B., Mao, W., Gratch, J. and Marsella, S. (2005) Mitigation theory: An integrated approach. Proceedings of Cognitive Science, Stresa, 21-23 July 2005.

[29] Martinovski, B., Traum, D. and Marsella, S. (2005) Rejection of empathy and its linguistic manifestations. Proceedings of Conference on Formal and Informal Negotiation, Ottawa, 26-27 May 2005.

[30] Martinovski, B. (2009) Emotion as an argumentation engine: Modeling the role of emotion in negotiation. Journal of Group Decision and Negotiation, 18, 235-261. http://dx.doi.org/10.1007/s10726-008-9153-7

[31] Erturk, Y. (2009) Towards a post-patriarchal gender order: Confronting the universality and the particularity of violence against women. Sociologisk Forskning (National Sociological Journal of Sweden), 46, 61-70.

[32] Hanafi, S. (2010) Modes of incorporation of the Palestinian protracted refugees: Some theoretical considerations. Presented at XVII ISA World Congress, Gothenburg.

[33] Dona, G. (2010) Challenging the exclusivity of ethnicity in ethnic conflicts. Presented in the Violence and Ethnical Conflict Session of XVII ISA World Congress of Sociology, Gothenburg.

[34] Cohen, S. (2001) States of denial. Knowing about atrocities and suffering. Polity, Cambridge.

[35] Rose, F.D., Brooks, B.M. and Rizzo, A.A. (2005) Virtual reality in brain damage rehabilitation: Review. Cyber Psychology \& Behavior, 8, 241-262. http://dx.doi.org/10.1089/cpb.2005.8.241

[36] Levi, P. (1989) The drowned and the saved. Vintage International, New York.

[37] Spiegelman, A. (1991) The MAUS: A survivor's tale. Pantheon Books, Apex Novelties.

[38] Iles, P. (1995) Learning to work with difference. Personnel Review, 24, 44-60.

[39] Hofstede, G. (1996) Cultures and organizations: Software of the mind: Intercultural cooperation and its importance for survival. McGraw-Hill, New York.

[40] Enayati, J. (2002) The research: Effective communication and decision-making in diverse groups. In: Hemmati, M., Ed., Multi-Stakeholder Processes for Governance and Sustainability: Beyond Deadlock and Conflict, Earthscan Publications Ltd., London.

[41] Halverson, C.B. and Tirmizi, S.A. (2008) Effective multi-cultural themes: Theory and practice. Springer, Amsterdam. http://dx.doi.org/10.1007/978-1-4020-6957-4

[42] Reeh, A., Aydin, S., Moréno, J., García, M.J., Mota, G.R. and Martinovski, B. (2009) Body language in intercultural and cross-cultural communication. Proceedings of 16th NIC Conference on Intercultural Communication. College of Borås, Borås, 26-28 November 2009.

[43] Gumperz, J. (1982) Discourse strategies. Cambridge University Press, Cambridge. http://dx.doi.org/10.1017/CBO9780511611834

[44] Qui, C. and Wang, X. (2010) Comparison of business negotiation styles between China and Sweden: An experimental role-play according to accommodation theory. Master Thesis Supervised by B. Martinovski, Gothenburg University, Gothenburg.

[45] Kopp, R. (2005) Communication challenges between Americans and Japanese in the workplace. Transcultural Management Review, 2, 70-77.

[46] Mandela, N. (1995) A long walk to freedom. Little Brown \& Co., New York.

[47] Agerström, J. and Björklund, F. (2009) Moral concerns are greater for temporally distant events and are moderated by value strength. Social Cognition, 27, 261-282.

[48] Liberman, N. and Trope, Y. (2003) Temporal construal theory of intertemporal judgment and decision. In: Loewenstein, G., Read, D. and Baumeister, R., Eds., Time and Choice: Economic and Psychological Perspectives on Intertemporal Choice, Sage, New York, 217-240. 
[49] Thagard, P. (2010) The brain and the meaning of life. Princeton University Press, Princeton.

[50] Martinovski, B. (2007) Shifting attention as re-contextualization in negotiation. Proceedings of GDN 2007, Montreal, 14-17 May 2007.

[51] Martinovski, B. (2010) Emotion in Negotiation. In: Kilgour, M. and Eden, C., Eds., Handbook on Group Decision and Negotiation. Springer, Amsterdam.

[52] Maemura, Y. and Horita, M. (2012) Humour in negotiations: A pragmatic analysis of humour in simulated negotiations. Journal of Group Decision and Negotiation, 21, 821-838. http://dx.doi.org/10.1007/s10726-011-9251-9 